\title{
Microstructural and durability effects in mortars after 1500 hardening days regarding the addition of volcanic powder of the Calbuco volcano (Chile) as clinker replacement ${ }^{+}$
}

\author{
Rosa María Tremiño ${ }^{1}$, Teresa Real-Herraiz ${ }^{2}$, Viviana Letelier ${ }^{3}$ and José Marcos Ortega 1,* \\ 1 Departamento de Ingeniería Civil, Universidad de Alicante, Ap. Correos 99, 03080, Alacant/Alicante, Spain; \\ jm.ortega@ua.es (J.M.O.) \\ 2 Instituto de Matemática Multidisciplinar, Universidad Politécnica de Valencia, Camino de Vera s/n, 46022, \\ Valencia, Spain; tereaher@upv.es (T.R.-H.) \\ 3 Departamento de Obras Civiles, Universidad de la Frontera, Av. Fco. Salazar, Temuco 01145, Chile; \\ viviana.letelier@ufrontera.cl (V.L.) \\ * Correspondence: rmta2@alu.ua.es; Tel.: +34-96-5903-400 (R.M.T.) \\ + Presented at the 1st International Electronic Conference on Applied Sciences, \\ 10-30 November 2020; Available online: https://asec2020.sciforum.net/
}

Published: 9 November 2020

\begin{abstract}
Nowadays, the cement industry still constitutes an important pollutant industrial sector. Then, the strategies to reduce its environmental impact are a popular topic of research. One of these strategies consists of partially replacing clinker with other materials. Here, it has been analyzed the effects at 1500 hardening days of the addition of volcanic powder on the microstructure and durability properties of mortars that incorporate $10 \%$ and $20 \%$ of this addition as clinker replacement. Reference mortars prepared with ordinary Portland cement without additions were also studied. The volcanic powder has been obtained from the last eruption of the Calbuco volcano, placed in the southern Andes between the cities of Ensenada and Puerto Montt (Chile). The mortars were kept in an optimum condition $\left(20^{\circ} \mathrm{C}\right.$ and $100 \%$ relative humidity) until the testing age. Their microstructure has been characterized using mercury intrusion porosimetry and impedance spectroscopy. As durability parameters, the steady-state chloride diffusion coefficient and the absorption after immersion were determined. According to the results obtained, mortars with volcanic powder showed similar porosities and more refined microstructure compared to reference mortars. Furthermore, the durability properties at 1500 hardening days of mortars which incorporate volcanic powder were adequate, especially regarding the resistance against chloride ingress.
\end{abstract}

Keywords: sustainability; volcanic powder; very long term effects; microstructure; durability.

\section{Introduction}

Today, the cement industry still constitutes an important pollutant industrial sector. Therefore, the strategies to reduce its environmental impact are a popular topic of research. One of these strategies consists of replacing partially clinker with other supplementary cementitious materials $[1,2]$, such as additions. Recently, several researches [3,4] have revealed that volcanic powder could have a good performance as addition for cement-based materials. However, these studies have analyzed the effect of volcanic powder at relatively short hardening ages, and the required service life of materials used for building real structures is much longer. 
Then, the main purpose of this work is to study the effects in the very long-term (1500 hardening days) of the addition of volcanic powder on the microstructure and durability properties of mortars that incorporate $10 \%$ and $20 \%$ of volcanic powder as clinker replacement.

\section{Materials and Methods}

\subsection{Materials and sample preparation}

The volcanic powder (VP) used in this research came from the last eruption of the Calbuco volcano $\left(41^{\circ} 20^{\prime} \mathrm{S}, 72^{\circ} 37^{\prime} \mathrm{W}, 2003\right.$ m.a.s.l.). It is located in the southern Andes, between the cities of Ensenada and Puerto Montt in Chile. Its last subplinian eruption occurred on April 22-23, 2015, Analyses of the erupted debris reveal the presence of porphyritic basaltic andesite ( $55 \%$ by weight of $\mathrm{SiO}_{2}$ ) [5]. The particle size distributions of the debris revealed particle fractions from $3 \mu \mathrm{m}$ to 350 $\mu \mathrm{m},[6]$. In this study, the volcanic powder was sifted and the VP particles used as an addition were less than $75 \mu \mathrm{m}$. The chemical analysis of the VP revealed that its main components are silica, aluminum and iron.

Three kinds of mortars are studied in this research. First of all, a reference mortar made only with ordinary Portland cement CEM I 42.5 R (Spanish and European standard UNE-EN 197-1 [7]), designed as REF in the results and discussion section. Regarding the specimens with VP addition, two different types of mortars were prepared, which incorporated a $10 \%$ and $20 \%$ as a replacement of the abovementioned cement CEM I $42.5 \mathrm{R}$. These mortars were respectively named as VP10 and VP20. The water to cement ratio was 0.5 and the aggregate to cement ratio was 3:1 for all the studied mortars. The fine aggregates accomplished the prescriptions of standard UNE-EN 196-1 [8].

Cylindrical specimens with $10 \mathrm{~cm}$ in diameter and $15 \mathrm{~cm}$ high were prepared. They were stored in a chamber at $20^{\circ} \mathrm{C}$ and $95 \%$ relative humidity $(\mathrm{RH})$ during the first 24 hours. After that, they were de-molded and cut for obtaining disks with $1 \mathrm{~cm}$ thickness.Finally, these samples were kept in an optimum laboratory condition $\left(20^{\circ} \mathrm{C}\right.$ and $\left.100 \% \mathrm{RH}\right)$ up to the testing age (1500 hardening days).

\subsection{Experimental techniques}

The microstructure of the mortars was characterized using mercury intrusion porosimetry and impedance spectroscopy.

In relation to mercury intrusion porosimetry, the porosimeter used was a Poremaster-60 GT model manufactured by Quantachrome Instruments (Boynton Beach, Florida, USA). Before the test, the specimens were dried in an oven at $50^{\circ} \mathrm{C}$ for 48 hours. The results analyzed in this work were total porosity, pore size distribution and percentage of $\mathrm{Hg}$ retained at the end of the experiment. Two measurements were made on each type of mortar.

Regarding the impedance spectroscopy, it allows to get global information of the pore structure of the samples [9,10]. In this work, the measurements were performed using an Agilent 4294A analyzer (Agilent Technologies, Kobe, Japan). This device takes capacitance measurements ranging between $10^{-14} \mathrm{~F}$ and $0.1 \mathrm{~F}$, with a maximum resolution of $10^{-15} \mathrm{~F}$. Circular electrodes with $8 \mathrm{~cm}$ diameter were used, consisting of flexible graphite attached to a piece of copper with the same diameter to obtain the impedance spectra. The frequencies ranged between $100 \mathrm{~Hz}$ and $100 \mathrm{MHz}$. Contacting and non-contacting methods were used [9]. The experimental data were fit to the equivalent circuits proposed by Cabeza et al. [36]. Those circuits consisted of several resistances and capacitances [10]. The $R_{1}$ resistance provides data about the percolating poresin the sample, the $R_{2}$ resistance provides information about the pores in general, the $\mathrm{C}_{1}$ capacitance provides information about the solid fraction of the sample, and the $C_{2}$ capacitance is associated with the surface of the pores in contact with the electrolyte that fills the pore network of the material [10]. Here, due to their greater accuracy, only the values of the parameters $R_{2}, C_{1}$ and $C_{2}$ with the non-contacting method are analyzed. The value of the $R_{1}$ resistance, which can be only obtained using the contacting method, was used for obtaining the steady-state chloride diffusion coefficient. Eight different disks were analyzed with this technique for each mortar type. 
The durability-related parameters analyzed in this research have been the absorption after immersion and the steady-state chloride diffusion coefficient.

The absorption after immersion was determined according to the ASTM Standard C642-06 [11] and six samples were tested for each kind of mortar studied.

The steady-state chloride diffusion coefficient has been obtained from the electrical resistivity of the saturated sample. The resistivity was calculated from the $R_{1}$ impedance spectroscopy values obtained in saturated samples. As has been previously explained, the $R_{1}$ impedance resistance is related to the pores that cross the sample [9] and is therefore equivalent to the electrical resistance of the sample [12]. For each binder, six different samples were tested. Finally, the steady-state diffusion coefficient was calculated using the following expression [33]:

$$
\mathrm{D}_{\mathrm{S}}=\frac{2 \times 10^{-10}}{\rho}
$$

where: $D_{s}$ is the chloride steady-state diffusion coefficient through the sample $\left(\mathrm{m}^{2} / \mathrm{s}\right)$ and $\rho$ is the electrical resistivity of the specimen $(\Omega \cdot \mathrm{m})$.

\section{Results and discussion}

Below were shown the results of total porosity, the pore size distributions and the percentage of mercury retained at the end of the experiment in the mortars after 1500 hardening days. The pore size distribution was analyzed considering the next diameter intervals: $<10 \mathrm{~nm}, 10-100 \mathrm{~nm}, 100 \mathrm{~nm}$ to $1 \mu \mathrm{m}, 1-10 \mu \mathrm{m}, 10 \mu \mathrm{m}$ to $0.1 \mathrm{~mm}$, and $>0.1 \mathrm{~mm}$

The results for total porosity are represented in Figure 1.a. The porosity of VP samples increased as the percentage of VP rose. On the one hand, the VP10 mortar showed a very similar porosity to the reference one at 1500 days of hardening. On the other hand, for the VP20 samples, the porosities were scarce higher than those presented by the reference cement.

Regarding the porous structure of the specimens with VP (see Figure 1.b), it was more refined for both the VP10 and VP20 ones than for the reference mortar at 1500 hardening days, as suggested the higher volume of pores with diameters lower than $100 \mathrm{~nm}$, and especially those in the range $<10$ $\mathrm{nm}$. This fact would be indicative of the beneficial effect in the very long term of VP addition, produced by the formation of new solid phases as products of pozzolanic reactions of volcanic powders, entailing a closer microstructure.

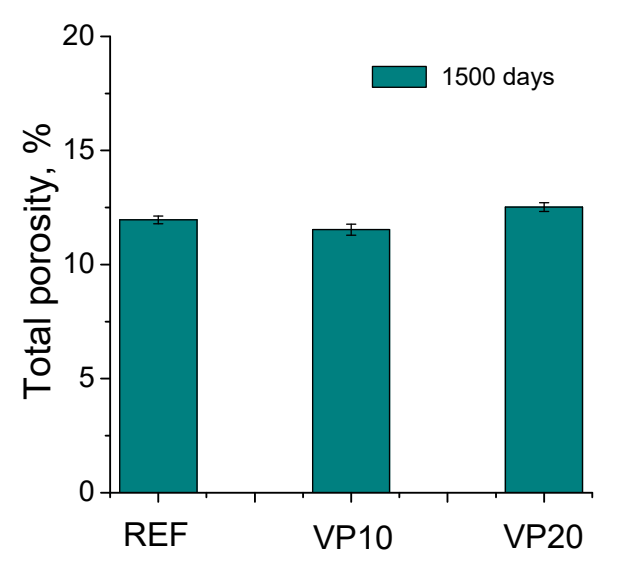

(a)

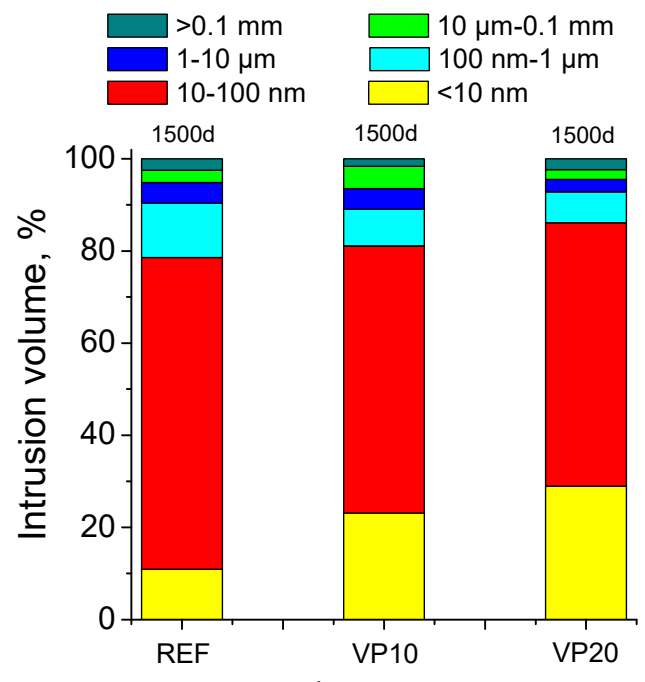

(b)

Figure 1. (a) Total porosity results of the mortars studied; (b) Pore size distributions of the analyzed mortars.

With respect to the percentage of $\mathrm{Hg}$ retained in the samples at 1500 hardening days, the Figure 2.a shows that the values of this parameter obtained for VP mortars were greater than those for the 
reference specimens. The percentage of $\mathrm{Hg}$ retained provides information about the tortuosity of the pore network of the material. Therefore, the abovementioned result would suggest that VP specimens had a higher pore network refinement, coinciding with the pore size distribution results previously described and discussed.

In relation to impedance spectroscopy results, in the Figure $2 . b$ it can be observed that the capacitance $C_{1}$ values noted for the VP10 and VP20 samples were relatively similar to those noted for reference specimens at 1500 hardening days. This parameter gives data about the solid fraction of the samples [9]. Consequently, the $C_{1}$ capacitance should increase when solids are formed as a consequence of the development of clinker hydration and pozzolanic VP reactions. This parameter does not depend on the distribution of the pore diameters. Therefore, the $C_{1}$ values at 1500 hardening days would indicate that the solid fraction of VP10, VP20 and reference mortars was similar. In view of that, the results of $C_{1}$ agree with the total porosity results obtained for all the mortar types analyzed, since they also show very similar values independently of the binder.

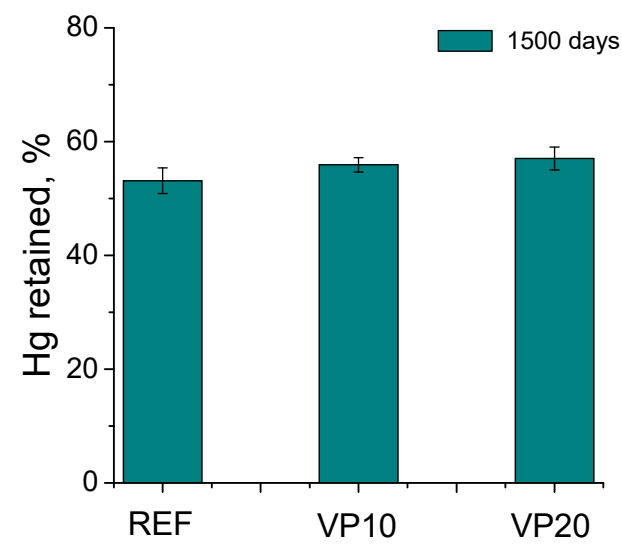

(a)

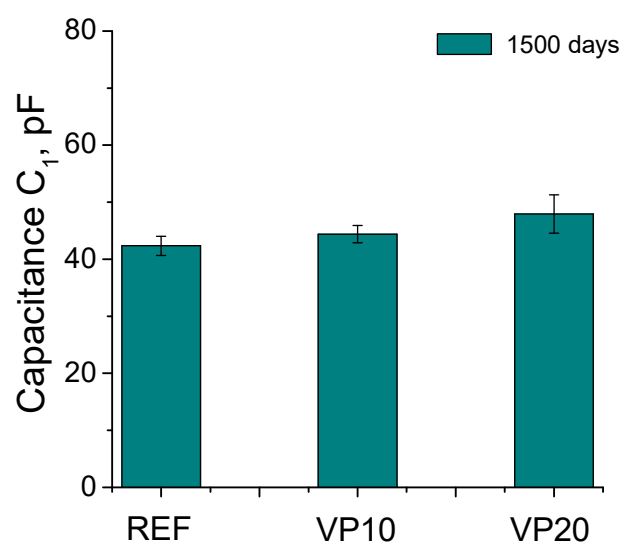

(b)

Figure 2. (a) Percentage of mercury retained at the end of the mercury intrusion porosimetry test for the binders studied; (b) Impedance spectroscopy $C_{1}$ capacitance for the mortars studied.

The results of the $\mathrm{C}_{2}$ capacitance of the different samples analyzed are represented in Figure 3.a. This parameter is related to the surface of the pores that are in contact with the electrolyte retained in the pores network of the material [14]. Therefore, this parameter is linked to the formation of the C-S-H gel layer, which progressively fills the pores. The C-S-H gel is formed on the surface of the pores and would produce rough structures that increase the specific surface of the pore, as well as the tortuosity of the microstructure. This increase in the specific pore surface is linked with an increase in the solid-electrolyte interface, which results in higher values of $C_{2}$ capacitance. At 1500 hardening days, the $\mathrm{C}_{2}$ capacitance values were noticeably higher for the samples VP10 and VP20 in comparison with the reference mortar. These results would be in keeping with the higher pore refinement noted for VP mortars in their pore size distributions by intervals, explained in relation to the effects of pozzolanic reactions of the volcanic powders in the microstructure.

The results of $R_{2}$ resistance is depicted in Figure 3.b. This resistance is related to the electrolyte that fills the pores in the specimen [9]. At 1500 hardening days, the $\mathrm{R}_{2}$ values were higher when greater is the VP content in the sample. This would indicate that the addition of VP increased the relative volume of smaller pores, being also in agreement with porosimetry and capacitance $\mathrm{C}_{2}$ results already discussed.

Regarding the absorption after immersion parameter, the measurements for the mortars analyzed are represented in Figure 4.a. The percentage of water absorption at 1500 hardening days was slightly higher in VP20 samples. However, the percentages of absorption in VP10 and reference samples were very similar.

Finally, the results of the steady-state chloride diffusion coefficient obtained from the resistivity of the saturated sample at 1500 hardening days are shown in Figure 4.b. It can be seen that the 
samples with VP presented lower values than reference mortars, which would indicate a very good performance of this addition regarding chloride ingress resistance. This result could be related to the greater refinement of the microstructure of the VP10 and VP20 mortars with respect to reference ones. The presence of a greater proportion of pores with smaller diameters would make more difficult the migration of aggressive chloride ions through the material, which would lead to lower values of the diffusion coefficient, as has been observed.

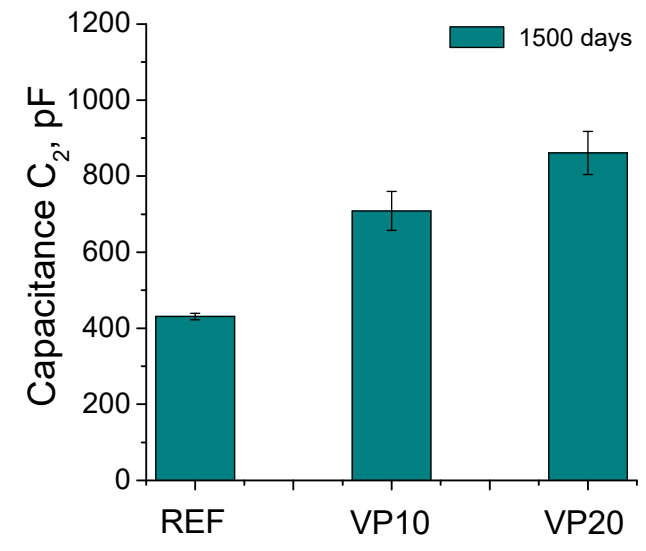

(a)

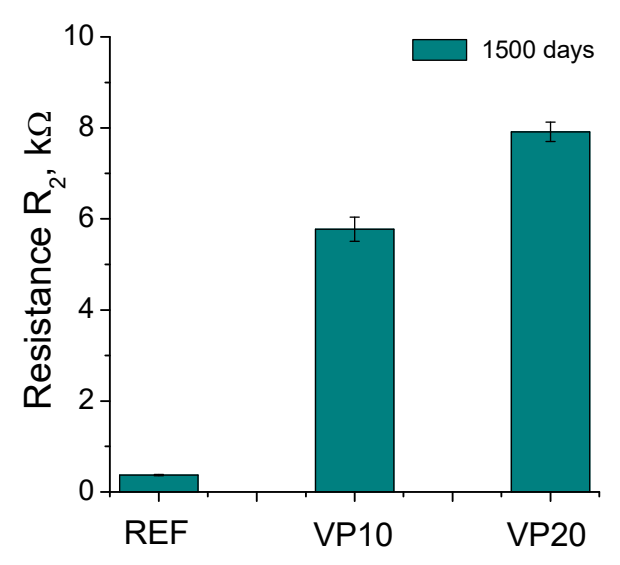

(b)

Figure 3. (a) Impedance spectroscopy $C_{2}$ capacitance for the mortars studied; (b) Impedance spectroscopy $\mathrm{R}_{2}$ resistance for the mortars studied.

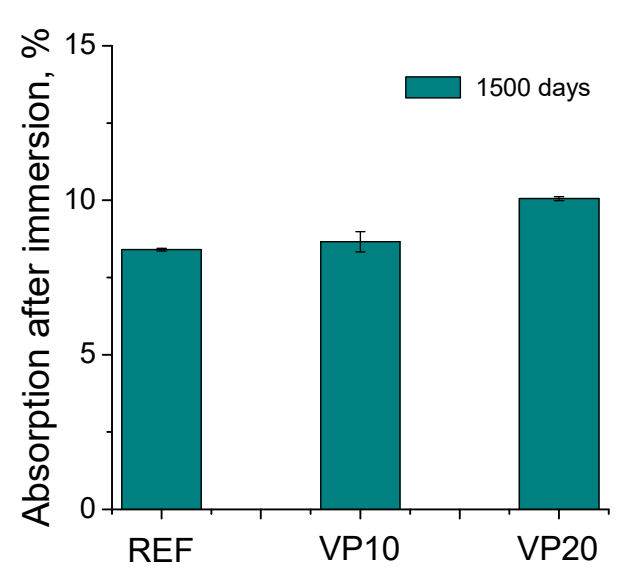

(a)

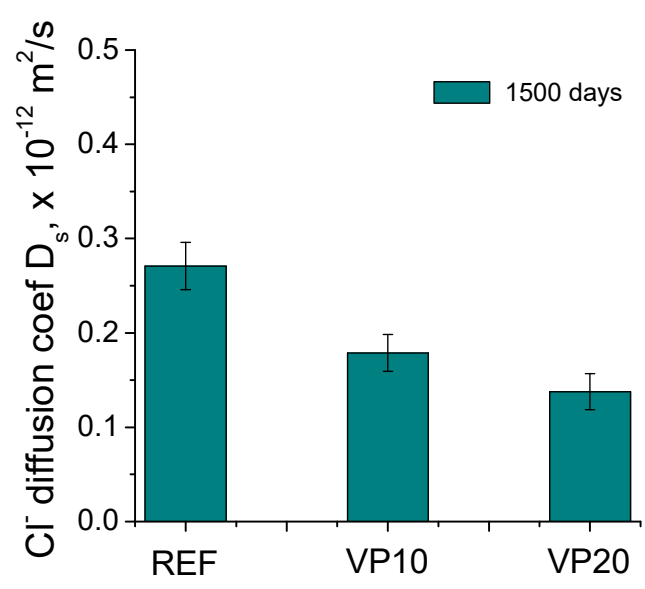

(b)

Figure 4. (a) Results of absorption after immersion parameter for the mortars analyzed; (b) Steady-state chloride diffusion coefficients obtained for the different binders studied.

\section{Conclusions}

The main conclusions to be drawn from the results previously discussed can be summarized as follows:

- At 1500 hardening days, the VP mortars showed a greater refinement of the pore structure in comparison with the reference mortars. This fact would be indicative of the beneficial effect in the very long term of this addition, produced by the formation of new solid phases as products of pozzolanic reactions of volcanic powders

- The results at 1500 days obtained using the non-destructive impedance spectroscopy technique were overall in agreement with the results obtained with mercury intrusion porosimetry. 
- The durability properties in the very long term analyzed in this work were overall adequate for VP mortars, highlighting their very good performance regarding chloride ingress resistance.

Author Contributions: Conceptualization, V.L. and J.M.O.; methodology, V.L., T.R.-H. and J.M.O.; investigation, R.M.T., T.R.-H., V.L. and J.M.O.; data curation, R.M.T. and J.M.O.; writing-original draft preparation, R.M.T.; writing - review and editing, J.M.O.; supervision, T.R.-H. and J.M.O.; The results included in this paper have been obtained in the PhD thesis carried out by R.M.T. at University of Alicante (Spain), under the supervision of J.M.O. and T.R.-H..

Funding: This research received no external funding.

Acknowledgments: Authors wish to thank Cementos Portland Valderrivas S.A. for providing the ordinary Portland cement used in this study.

Conflicts of Interest: The authors declare no conflict of interest.

\section{References}

1. Palankar, N.; Ravi Shankar, A. U.; Mithun, B. M. Durability studies on eco-friendly concrete mixes incorporating steel slag as coarse aggregates. J. Clean. Prod. 2016, 129, 437-448, doi:10.1016/j.jclepro.2016.04.033.

2. Pasupathy, K.; Berndt, M.; Castel, A.; Sanjayan, J.; Pathmanathan, R. Carbonation of a blended slag-fly ash geopolymer concrete in field conditions after 8 years. Constr. Build. Mater. 2016, 125, 661-669, doi:10.1016/j.conbuildmat.2016.08.078.

3. Labbaci, Y.; Labbaci, B.; Abdelaziz, Y.; Mekkaoui, A.; Alouani, A. The use of the volcanic powders as supplementary cementitious materials for environmental-friendly durable concrete. Constr. Build. Mater. 2017, 133, 468-481, doi:10.1016/j.conbuildmat.2016.12.088.

4. Seddik Meddah, M. Durability performance and engineering properties of shale and volcanic ashes concretes. Constr. Build. Mater. 2015, 79, 73-82, doi:10.1016/j.conbuildmat.2015.01.020.

5. Romero, J. E.; Morgavi, D.; Arzilli, F.; Daga, R.; Caselli, A.; Reckziegel, F.; Viramonte, J.; Díaz-Alvarado, J.; Polacci, M.; Burton, M.; Perugini, D. Eruption dynamics of the 22-23 April 2015 Calbuco Volcano (Southern Chile): Analyses of tephra fall deposits. J. Volcanol. Geotherm. Res. 2016, 317, 15-29, doi:10.1016/j.jvolgeores.2016.02.027.

6. Reckziegel, F.; Bustos, E.; Mingari, L.; Báez, W.; Villarosa, G.; Folch, A.; Collini, E.; Viramonte, J.; Romero, J.; Osores, S. Forecasting volcanic ash dispersal and coeval resuspension during the April-May 2015 Calbuco eruption. J. Volcanol. Geotherm. Res. 2016, 321, 44-57, doi:10.1016/j.jvolgeores.2016.04.033.

7. AENOR UNE-EN 197-1:2011. Composición, especificaciones y criterios de conformidad de los cementos comunes. 2000, 30.

8. AENOR UNE-EN 196-1:2005. Métodos de ensayo de cementos. Parte 1: Determinación de resistencias mecánicas 2005.

9. Cabeza, M.; Merino, P.; Miranda, A.; Nóvoa, X. R.; Sanchez, I. Impedance spectroscopy study of hardened Portland cement paste. Cem. Concr. Res. 2002, 32, 881-891, doi:10.1016/S0008-8846(02)00720-2.

10. Cabeza, M.; Keddam, M.; Nóvoa, X. R.; Sánchez, I.; Takenouti, H. Impedance spectroscopy to characterize the pore structure during the hardening process of Portland cement paste. Electrochim. Acta 2006, 51, 1831-1841, doi:10.1016/J.ELECTACTA.2005.02.125.

11. ASTM ASTM C642 - 06 Standard Test Method for Density, Absorption, and Voids in Hardened Concrete 2006, 3.

12. Ortega, J. M.; Sánchez, I.; Antón, C.; De Vera, G.; Climent, M. A. Influence of environment on durability of fly ash cement mortars. ACI Mater. J. 2012, 109.

13. Andrade, C.; Alonso, C.; Arteaga, A.; Tanner, P. Methodology based on the electrical resistivity for the calculation of reinforcement service life; 2001; Vol. 764;.

14. Cabeza, M.; Keddam, M.; Nóvoa, X. R.; Sánchez, I.; Takenouti, H. Impedance spectroscopy to characterize the pore structure during the hardening process of Portland cement paste. Electrochim. Acta 2006, 51, 1831-1841, doi:10.1016/j.electacta.2005.02.125. 